\title{
Prevalence, severity and underdiagnosis of COPD in the primary care setting
}

\author{
M Bednarek, ${ }^{1} \mathrm{~J}$ Maciejewski, ${ }^{2}$ M Wozniak, ${ }^{2}$ P Kuca, ${ }^{3}$ J Zielinski
}

\section{See Editorial, p 387}

- Supplementary table 1 and figs 1 and 2 are published online only at http://thorax.bmj.com/ content/vol63/issue5

${ }^{1}$ 2nd Department of Respiratory Medicine, National Research Institute of Tuberculosis and Lung Diseases, Warsaw, Poland;

${ }^{2}$ Primary Care Practice

"Medicar", Sierpc, Poland;

${ }^{3}$ Cardio-Pulmonary Intensive

Care Unit, National Research Institute of Tuberculosis and Lung Diseases, Warsaw, Poland

Correspondence to:

Dr M Bednarek, 2nd Department of Respiratory Medicine,

National Research Institute of

Tuberculosis and Lung Diseases, 26 Plocka St, Warsaw 01-138,

Poland; m.bednarek@

igichp.edu.pl

Received 12 June 2007

Accepted 4 December 2007

Published Online First

30 January 2008

\begin{abstract}
Background: Chronic obstructive pulmonary disease (COPD) is a common disease with a steadily increasing prevalence and mortality. However, recent epidemiological estimates differ depending on the population studied and methods used.
\end{abstract}

Aim: To investigate the prevalence, severity and burden of COPD in a primary care setting.

Methods: From 4730 patients registered in a single primary care practice, all 2250 patients aged 40 years or more were invited to participate. Participants completed a questionnaire on smoking, respiratory symptoms, education and social status. A physical examination was followed by pre- and post-bronchodilator (BD) spirometry. Results: Of the eligible patients, 1960 (87\%) participated. $92 \%$ of spirometric tests met the ATS criteria. Airflow limitation was demonstrated in $299(15 \%)$ of the participants pre-BD and in $211(11 \%)$ post-BD. COPD was diagnosed in 183 patients (9.3\%). Of these patients, the degree of post-BD airflow limitation was mild in $30.6 \%$, moderate in $51.4 \%$, severe in $15.3 \%$ and very severe in $2.7 \%$. Only $18.6 \%$ of these patients had previously been diagnosed with COPD; almost all of these had severe or very severe airflow limitation. As a result of the study, a diagnosis of asthma was made in 122 patients.

Conclusions: The prevalence and underdiagnosis of COPD in adult patients in this primary care setting made case finding worthwhile. Large numbers of newly detected patients were symptomatic and needed treatment. Limiting investigations to smokers would have reduced the number of COPD diagnoses by $26 \%$.

Chronic obstructive pulmonary disease (COPD) is a common disabling disease. Mortality from COPD is increasing worldwide. ${ }^{1}$ Prevalence estimates of COPD differ largely depending on the diagnostic instruments used and the population studied. ${ }^{2}$ Other major sources of difference in COPD prevalence estimates are related to different spirometric criteria for bronchial obstruction (forced expiratory volume in $1 \mathrm{~s} /$ forced vital capacity $\left(\mathrm{FEV}_{1} / \mathrm{FVC}\right)$ fixed ratio versus lower limit of normal), type of spirometric test (pre- or postbronchodilator (BD)) and a cut-off level of $\mathrm{FEV}_{1}$ per cent predicted ( $>80 \%$ or $<80 \%$ of predicted). According to American Thoracic Society/European Respiratory Society (ATS/ERS) ${ }^{3}$ and Global Initiative on Obstructive Lung Disease guidelines, ${ }^{4}$ a presumptive diagnosis of COPD should be confirmed by spirometry. Meta-analysis of epidemiological investigations based on spirometry testing showed a COPD prevalence of $9-10 \%{ }^{5}$

The prevalence of physician diagnosed COPD is much lower than suggested by population based spirometric surveys: $1.5 \%$ in the $\mathrm{UK}^{6}$ and $3 \%$ in
Canada. $^{7}$ Thus only a fraction of those with COPD have been diagnosed $\left(9.4 \%^{8}\right.$ to $\left.22 \%{ }^{9}\right)$. The aim of our study was to investigate in the primary care setting: (1) the prevalence and severity of COPD in adult patients; (2) the fraction already diagnosed and treated and (3) COPD risk factors.

\section{METHODS}

The study was performed in Sierpc, Poland, a town with 20000 inhabitants. There are no significant sources of air pollution in the town itself or within a perimeter of $50 \mathrm{~km}$.

Investigations were performed in one of three primary care practices in Sierpc. This practice cares for both urban and rural populations. Two full time primary care physicians care for a total of 4730 registered patients (children and adults).

All patients registered at the primary care practice aged 40 years or more were invited to participate. Of the 2250 eligible adult patients, 967 (43\%) were men; 1462 lived in Sierpc and 788 lived in a nearby village.

Full investigations were performed in 1960 patients, $87.1 \%$ of those eligible; 174 (7.7\%) patients refused to participate, 90 (4\%) were unable to attend (handicapped by stroke, with impaired mental functions, or poor performance status due to malignancy or other debilitating disease) and $26(1.2 \%)$ patients were unable to perform valid spirometric tests. Age and sex structure of the participating patients did not differ from those of the population of Sierpc (see supplementary table 1 online).

Adult patients were recruited by personalised letter from the primary care physician explaining the nature and aim of the study. Causes, symptoms, signs and the natural history of COPD were described. The importance of early diagnosis for prevention of severe life threatening disease was emphasised. The higher risk of lung cancer, coronary artery disease and stroke in patients with abnormal spirometry results was also mentioned. A practice nurse then called eligible patients to arrange a convenient time for an office visit. A home visit was arranged for 80 patients who expressed difficulty coming to the office for the study.

Each visit started with weight and height measurements, and completion of a questionnaire with questions on details of birth, smoking habits, dyspnoea, ${ }^{10}$ education, economic status, environmental or professional exposure to dusts, fumes or smoke, and a history of respiratory diseases.

Spirometry testing was performed using a portable battery powered spirometer (EasyOne Diagnostic, model 2001; ndd Medical 
Technologies, Zurich, Switzerland). The spirometer measures flow using ultrasound transit time principles. Measurements were performed with the patient in a sitting position without a noseclip. Forced expiratory manoeuvres were repeated until three acceptable and reproducible tests were obtained. ${ }^{11}$ The best $\mathrm{FEV}_{1}$ and $\mathrm{FVC}$ were recorded, and the $\mathrm{FEV}_{1} / \mathrm{FVC}$ ratio was calculated. In patients with $\mathrm{FEV}_{1} / \mathrm{FVC}$ below the fifth percentile of the predicted value in baseline spirometry, $200 \mu \mathrm{g}$ of salbutamol were given by inhalation delivered through a spacer device and spirometry was repeated 15 min later (post$\mathrm{BD})$.

Spirometry tests were performed by two primary care nurses who had been trained in two separate $4 \mathrm{~h}$ sessions in a reference lung function laboratory at the National Research Institute of $\mathrm{TB}$ and Lung Diseases in Warsaw, Poland. The results of spirometric tests (numbers, flow/volume and volume/time curves) were sent electronically to one of the authors (MB) for quality control. Overall, $91.8 \%$ of the tests fulfilled the ATS goals for a good quality test session. The remaining $8.2 \%$ of tests were also included in the analysis as they all showed results above predicted values and were accepted as normal. Staging of COPD using post-BD spirometry results was performed according to ATS/ERS guidelines ${ }^{3}$ using ECCS predicted values. ${ }^{12}$

The study was approved by the local institutional review board, and all participating patients gave written informed consent.

Statistical analyses were performed using Statistica V.6.0 software (StatSoft, Inc., V.2001, Tulsa, Oklahoma, USA). Tests were considered significant when $p<0.05$. Data distribution was analysed using the Kolmogorov-Smirnov test with Lilliefors correction. Quantitative data were described using mean (SD). Between group characteristics were described using $t$ tests or analysis of variance. Homogeneity of variance was assessed using Levene's test. If a variable demonstrated normal distribution and homogenous variance, the F ANOVA test was applied. Otherwise, a non-parametric Kruskal-Wallis H test was used. To characterise the strength of relationships between continuous variables, Pearson correlations were used. Categorised, qualitative, between groups analyses were performed using the Pearson $\chi^{2}$ test with appropriate corrections for N. Pre-test probability for post-BD airflow limitation was assessed using logistic regression models.

\section{RESULTS}

A total of 1960 patients were investigated, $87.1 \%$ of the eligible cohort. There were 1196 women (93\% of eligible) and 764 men
(79\% of eligible) in the studied group (table 1). Mean age was 56.7 (11.6) years (range 40-93 in men and 40-91 in women). Approximately two-thirds of patients lived in town.

\section{Spirometry}

The pre-BD $\mathrm{FEV}_{1} / \mathrm{FVC} \%$ was below the fifth percentile in 299 patients $(15.3 \%)$. Airflow obstruction was present post-BD in 211 patients (29.4\% fewer than pre-BD) (see supplementary figs 1 and 2 online). From 88 patients in whom the FEV 1 FVC ratio returned to normal, $60 \%$ presented with mild and $40 \%$ with moderate airflow obstruction.

In all subjects with post-BD airflow obstruction, patients' notes were inspected for a history of respiratory events in the past and earlier respiratory diagnoses. In 20 patients there was a history of asthma documented by attacks of dyspnoea, remissions, eosinophilia and in some patients positive results of prick tests. In eight patients, additional tests were performed (white blood differential count, IgE, prick test) confirming a diagnosis of asthma. Fourteen patients showed a large bronchodilating response. This was considered as suggestive of asthma but only in combination with other symptoms and signs. This resulted in separation of 28 patients with a diagnosis of asthma and airflow obstruction which was not fully reversible. COPD was diagnosed in 183 patients (9.3\%) $(12.8 \%$ of males and $7.1 \%$ of females). The mean increase in $\mathrm{FEV}_{1}$ post$\mathrm{BD}$ was $1.2(8.5) \%$. The majority of patients with COPD had mild $(30.6 \%)$ or moderate $(51.4 \%)$ disease. Only $15.3 \%$ had severe and $2.7 \%$ very severe disease (table 2 ). Ventilatory impairment in female COPD patients was less severe, with a mean $\mathrm{FEV}_{1} \%$ of predicted of $71(18.3) \%$ versus $64(20) \%$ in males (table 3).

The prevalence of COPD increased with age, from $5.2 \%$ in the fifth decade to $16.8 \%$ in patients aged 70 years or more, reaching $28.5 \%$ in males (fig 1 ). In women aged $70+$ years, there was no further increase in COPD prevalence. Sixteen of 19 women in this age group were never smokers.

To analyse the pre-test probability for a COPD diagnosis, a model of logistic regression was applied. The analysis revealed a role for smoking status, exertional dyspnoea, chronic phlegm production and gender as potential indicators of COPD in primary care (table 4$)$.

In 34 patients (18.6\%), COPD had already been diagnosed; 27 presented with severe and four with very severe stage COPD. Two patients with severe and one patient with very severe disease had not been previously diagnosed. There was no patient who had previously been diagnosed with COPD but had normal post-BD spirometry. A restrictive pattern of ventilatory

Table 1 Characteristics of eligible patients and participating patients

\begin{tabular}{|c|c|c|c|c|c|c|}
\hline \multirow[b]{2}{*}{ Age (y) } & \multicolumn{2}{|l|}{ Males } & \multicolumn{2}{|l|}{ Females } & \multirow[b]{2}{*}{$\chi^{2}$} & \multirow[b]{2}{*}{ p Value } \\
\hline & $\begin{array}{l}\text { Eligible } \\
\text { (n) }\end{array}$ & $\begin{array}{l}\text { Investigated } \\
\text { (n (\%)) }\end{array}$ & $\begin{array}{l}\text { Eligible } \\
\text { (n) }\end{array}$ & $\begin{array}{l}\text { Investigated } \\
\text { (n (\%)) }\end{array}$ & & \\
\hline $40-49$ & 313 & $253(76.7)$ & 418 & 407 (97.4) & 2.708 & 0.099 \\
\hline $50-59$ & 272 & $252(92.6)$ & 371 & $358(96.5)$ & 0.089 & 0.766 \\
\hline $60-69$ & 162 & $126(77.8)$ & 217 & $206(94.9)$ & 1.494 & 0.222 \\
\hline $70-79$ & 159 & $111(69.8)$ & 203 & $186(91.6)$ & 2.629 & 0.105 \\
\hline$\geqslant 80$ & 61 & $22(36.1)$ & 74 & $39(52.7)$ & 1.082 & 0.298 \\
\hline Total & 967 & $764(79.0)$ & 1283 & $1196(93.2)$ & 6.752 & 0.009 \\
\hline Current smokers & & $301(39.4)$ & & $279(23.3)$ & 30.14 & 0.0001 \\
\hline Ex-smokers & & $286(37.3)$ & & $202(16.9)$ & 60.65 & 0.0001 \\
\hline Never smokers & & $177(23.3)$ & & 715 (59.8) & 100.7 & 0.0001 \\
\hline
\end{tabular}

$\chi^{2}$ test and $p$ values regarding age categories refer to differences between the eligible versus the investigated groups. $\chi^{2}$ test and $p$ values regarding smoking status refer to differences between men and women. 
Table 2 Spirometric classification of COPD severity

\begin{tabular}{lllcll}
\hline & \multicolumn{4}{l}{ Airflow obstruction } \\
\cline { 2 - 6 } & $\begin{array}{l}\text { Mild } \\
\text { (n (\%)) }\end{array}$ & $\begin{array}{l}\text { Moderate } \\
\text { (n (\%)) }\end{array}$ & $\begin{array}{l}\text { Severe } \\
\text { (n (\%)) }\end{array}$ & $\begin{array}{l}\text { Very severe } \\
\text { (n (\%)) }\end{array}$ & $\begin{array}{l}\text { Total } \\
\text { (n (\%)) }\end{array}$ \\
\hline Males & $24(24.5)$ & $50(51.0)$ & $21(21.4)$ & $3(3.1)$ & $98(53.6)$ \\
Females & $32(37.6)$ & $44(51.8)$ & $7(8.2)$ & $2(2.3)$ & $85(46.4)$ \\
Total & $56(30.6)$ & $94(51.4)$ & $28(15.3)$ & $5(2.7)$ & $183(100)$ \\
p Value & 0.25 & 0.94 & 0.09 & 0.87 & 0.41 \\
\hline
\end{tabular}

Post-bronchodilator American Thoracic Society/European Respiratory Society staging. ${ }^{3}$

COPD, chronic obstructive pulmonary disease.

impairment was found in 108 (5.5\%) patients ( $\mathrm{FEV}_{1} / \mathrm{FVC} \%$ above the fifth percentile and FVC $<80 \%$ of predicted).

\section{Symptoms}

Patients diagnosed with COPD frequently had symptoms: chronic cough (45\%), sputum production (38\%) and dyspnoea on exertion (52.5\%). Only 59 (32\%) did not report any symptom. Dyspnoea Medical Research Council grade 1 was reported by $43(23.5 \%)$, grade 2 by $36(19.7 \%)$, grade 3 by 12 $(6.6 \%)$ and grade 4 by five $(2.7 \%)$ patients. Relations between symptoms, COPD stage and smoking status are shown in table 5. The frequency and number of symptoms increased with disease severity.

\section{Smoking habits}

There was a large gender difference in smoking habits in the studied cohort. Only $23.3 \%$ of men were never smokers compared with $60 \%$ of women (table 1 ). This difference was even more pronounced in patients with COPD. Ninety-six per cent of men with COPD were ever smokers, with a mean tobacco exposure of 40 pack-years. Former smokers had a higher tobacco exposure (46.6 pack-years) than current smokers (35.5 pack-years). In female patients with COPD, 52\% were never smokers. Of the women who had ever smoked, 13\% were former smokers and $35 \%$ were current smokers, with a mean total tobacco exposure of 20 pack-years.

Initiation of smoking was earlier in men than in women $(p<0.0001)$. The intensity of tobacco smoking (cigarettes smoked per day) was twice as high in males than in females $(p<0.0001)$. Despite a lower cumulative exposure to nicotine in females, the difference in the Fagerström nicotine dependence test between males and females was lower than in tobacco exposure $(p<0.001)$ (table 1$)$.

\section{Other risk factors}

The relatively high prevalence of COPD in never smoking women led us to a post hoc case control survey on combustible material used by women for cooking (gas, coal or wood).
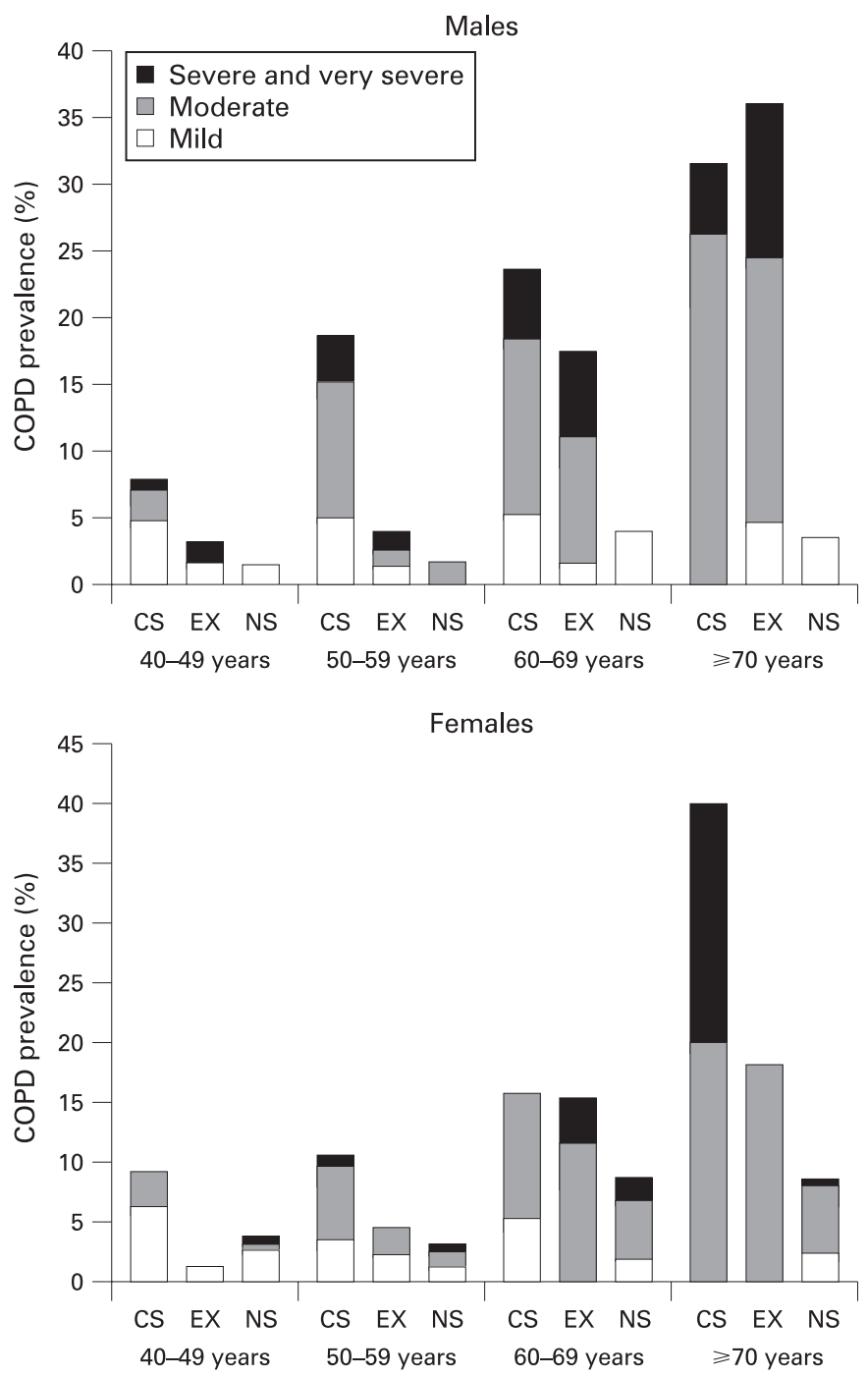

Figure 1 Prevalence and severity of chronic obstructive pulmonary disease (COPD) in relation to age and smoking status in males and females. CS, current smoker; EX, ex-smoker; NS, non-smoker.

Eighty-five never smoking women with COPD were compared with 85 age matched asymptomatic women with normal spirometry (healthy control subjects). Coal and wood material was used by $68.3 \%$ of women with COPD compared with $44.7 \%$ of healthy control subjects $(p<0.003)$. Never smoking patients with COPD (both sexes) were older $(p<0.0001)$, more frequently lived in rural areas $(p<0.001)$ and were more likely to have been born prematurely $(p<0.002)$ compared with patients with no respiratory problems.

Table 3 Spirometric variables in subjects with COPD

\begin{tabular}{llllllll}
\hline & Age $(\mathbf{y})$ & FEV $_{\mathbf{1}}(\mathbf{I})$ & $\begin{array}{l}\mathrm{FEV}_{\mathbf{1}} \\
\% \text { of pred }\end{array}$ & FVC (I) & $\begin{array}{l}\text { FVC } \\
\% \text { of pred }\end{array}$ & $\begin{array}{l}\mathbf{F E V}_{\mathbf{1}} / \mathbf{F V C} \\
\% \text { of pred. }\end{array}$ & $\begin{array}{l}\text { FEV } / \text { /FVC } \\
\text { RSD }\end{array}$ \\
\hline Males $(\mathrm{n}=98)$ & $63.4(11.0)$ & $2.00(0.84)$ & $64.2(20.3)$ & $3.61(1.1)$ & $92.0(19.8)$ & $70.8(11.8)$ & $-3.07(1.22)$ \\
Females $(\mathrm{n}=85)$ & $59.9(11.5)$ & $1.60(0.52)$ & $71.1(18.3)$ & $2.65(0.7)$ & $99.5(22.8)$ & $77.0(8.1)$ & $-2.73(0.96)$ \\
Total $(\mathrm{n}=183)$ & $61.7(11.3)$ & $1.83(0.75)$ & $67.2(19.7)$ & $3.2(1.1)$ & $95.2(21.4)$ & $73.5(10.8)$ & $-2.92(1.13)$ \\
$\mathrm{p}$ Value & 0.05 & 0.001 & 0.05 & 0.0001 & 0.05 & 0.0005 & 0.052 \\
\hline
\end{tabular}

Values are mean (SD).

$\mathrm{p}$ Values refer to difference between the genders.

COPD, chronic obstructive pulmonary disease; $\mathrm{FEV}_{1}$, forced expiratory volume in $1 \mathrm{~s}$; FVC, forced vital capacity; RSD, residual standard deviation. 
Table 4 Indicators for COPD in logistic regression model

\begin{tabular}{lclll}
\hline & $\begin{array}{l}\text { Regression } \\
\text { coefficient } \\
\text { (Beta) }\end{array}$ & $\begin{array}{l}\text { Standard } \\
\text { error }\end{array}$ & $\begin{array}{l}\text { Wald } \\
\text { probability (p) }\end{array}$ & $\begin{array}{l}\text { Exp(Beta) } \\
\mathbf{O R}\end{array}$ \\
\hline Ever smoker & 1.075 & 0.006 & $<0.0001$ & 2.93 \\
Dyspnoea on exertion & 0.772 & 0.003 & $<0.0001$ & 2.16 \\
Chronic phlegm production & 0.438 & 0.007 & $<0.0001$ & 1.55 \\
Gender (male) & 0.352 & 0.005 & $<0.0001$ & 1.42 \\
Age (y) & 0.021 & 0.0002 & $<0.0001$ & 1.02 \\
Chronic cough & -0.093 & 0.007 & $<0.0001$ & 0.91 \\
\hline
\end{tabular}

COPD, chronic obstructive pulmonary disease.

There was a significant relation between risk of developing COPD and educational level. Three-quarters of patients with COPD received only primary education compared with half of patients with no respiratory symptoms $(p<0.0001)$.

Low economic status was also associated with a higher risk of COPD compared with patients with no respiratory problems who more often declared satisfactory or good economic status $(p<0.0001)$.

\section{DISCUSSION}

In patients aged 40 years or more, from this primary care practice, the prevalence of COPD was $9.3 \%$. Only $19 \%$ of these patients had already been diagnosed and treated. Our results are strengthened by a high attendance rate (87\%) and very high accuracy of spirometry tests ( $92 \%$ met ATS goals).

The results of our investigations are consistent with the results of epidemiological surveys of COPD in Poland. In a representative population sample of Warsaw, aged 42-71 years, COPD was diagnosed in $10.7 \% .^{13}$ In a study performed in Silesia, a heavy polluted industrial region of Poland, the prevalence of COPD in 19-69-year-old adults was $10.2 \% .{ }^{14}$

We found a higher prevalence of severe COPD than reported in countrywide epidemiological surveys of COPD in adults. Fukuchi and colleagues ${ }^{8}$ found only $6 \%$ of adults with an $\mathrm{FEV}_{1}$ lower than $50 \%$ of predicted. Severe COPD was found in $13 \%$ of adults surveyed in Spain. ${ }^{9}$

We reduced overdiagnosis of COPD by using post-BD FEV 1 / FVC to diagnose COPD. There were other factors that may have prevented overdiagnosis of COPD, such as trained and supervised nurses, spirometer with quality grades and feedback. Others ${ }^{15}$ also reported a $27 \%$ lower prevalence of COPD by using post-BD spirometry instead of pre-BD spirometry (thereby excluding some people with asthma). We also reduced overdiagnosis of COPD by applying the fifth percentile of the $\mathrm{FEV}_{1}$ / FVC as a lower limit of normal ${ }^{16}$ instead of a fixed 0.7 ratio. ${ }^{17}{ }^{18}$

\section{Gender}

Our study did not confirm recent reports of a high prevalence of COPD among women. ${ }^{19}{ }^{20}$ That finding may reflect patterns of smoking in Poland, with $40 \%$ of males compared with $23 \%$ of females smoking. In our study, COPD was diagnosed in $12.8 \%$ of men and $7.1 \%$ of women. Only $50 \%$ of women diagnosed with COPD were current or ex-smokers. Also, total exposure to tobacco smoke was $50 \%$ lower in women than in men.. However, use of coal and biomass fuel by almost $70 \%$ of women with COPD may have influenced the rate of COPD in women. ${ }^{21}$ Severe and very severe COPD $\left(\mathrm{FEV}_{1}<50 \%\right.$ of predicted) was more than twice as frequent in men than in women $(24.5 \%$ vs $11.7 \%)$. Proportions of men and women with COPD in our study were similar to those reported by recent surveys on COPD prevalence in five major Latin American cites $^{22}$ and Norway. ${ }^{15}$

\section{Spirometry in primary care}

Our study confirmed that good quality spirometry testing can be accomplished in a primary care setting when several conditions are fulfilled. The spirometer model we selected met National Lung Health Education Program criteria for office spirometers, including instant manoeuvre quality checks and messages. ${ }^{23}$ This spirometer has been shown to retain long term accuracy. ${ }^{24}$ The two nurses performing the spirometry tests underwent two hands-on training courses in a reference pulmonary function laboratory. A strict quality assurance programme closely monitored and reported the quality of the test sessions.

Poor quality spirometry tests increase the risk of misinterpreting the results, causing unnecessary stress to patients because of falsely positive diagnoses. The cost and side effects of unnecessary treatment must also be considered. Low accuracy of spirometric tests in primary care was reported by Eaton and colleagues. ${ }^{25}$ However, more recent data from eight rural primary care practices in Canada showed good quality spirometry testing performed with a portable office spirometer. ${ }^{26}$ Under utilisation of spirometry in the diagnosis and management of COPD by primary care practitioners ${ }^{27}{ }^{28}$ has led some experts to question the value of widespread COPD case finding by primary care physicians. ${ }^{29}$ However, proper training and monitoring of test quality may produce low misclassification rates in selected primary care settings. ${ }^{30} 31$

Widespread use of good quality spirometric testing in primary care would have a positive impact on the diagnosis, management and prevention of severe stages of COPD when disability is substantial, quality of life poor and costs of treatment very high. ${ }^{4}$ Approximately $80 \%$ of patients with COPD have mild or moderate disease. Early diagnosis allows many more years for successful anti-smoking activities, ${ }^{32}$ counselling and smoking cessation treatment. ${ }^{33}$ Smoking cessation counselling combined with spirometry testing was shown to increase the smoking cessation rate in COPD patients in some studies, ${ }^{34}{ }^{35}$ but not in others. ${ }^{36}$ Long term follow-up of the Lung Health Study cohort

Table 5 Relations between symptoms, COPD stage and smoking status

\begin{tabular}{|c|c|c|c|c|c|c|c|c|}
\hline & \multicolumn{2}{|l|}{ Mild $(n=56)$} & \multicolumn{2}{|c|}{ Moderate $(n=94)$} & \multicolumn{2}{|c|}{ Severe $(n=28)$} & \multicolumn{2}{|c|}{ Very severe $(n=5)$} \\
\hline & $\begin{array}{l}\text { Ever smoker } \\
(\mathbf{n}=\mathbf{3 8})(\%)\end{array}$ & $\begin{array}{l}\text { Never smoker } \\
(\mathrm{n}=18)(\%)\end{array}$ & $\begin{array}{l}\text { Ever smoker } \\
(\mathrm{n}=70)(\%)\end{array}$ & $\begin{array}{l}\text { Never smoker } \\
(\mathrm{n}=24)(\%)\end{array}$ & $\begin{array}{l}\text { Ever smoker } \\
(n=24)(\%)\end{array}$ & $\begin{array}{l}\text { Never smoker } \\
(\mathrm{n}=4)(\%)\end{array}$ & $\begin{array}{l}\text { Ever smoker } \\
(\mathrm{n}=3)(\%)\end{array}$ & $\begin{array}{l}\text { Never smoke } \\
(n=2)(\%)\end{array}$ \\
\hline No symptoms & $13(34.2)$ & $12(66.7)$ & $23(32.9)$ & $7(29.2)$ & $4(16.7)$ & $1(25.0)$ & $0(0)$ & $0(0)$ \\
\hline Phlegm & $12(31.6)$ & $1(5.6)$ & $27(38.6)$ & $5(20.8)$ & $18(75.0)$ & $2(50.0)$ & $3(100)$ & $2(100)$ \\
\hline Dyspnoea & 18 (47.4) & $6(50.0)$ & 32 (45.7) & $12(50.0)$ & 23 (95.8) & $3(75.0)$ & $3(100)$ & $2(100)$ \\
\hline
\end{tabular}

COPD, chronic obstructive pulmonary disease. 
has clearly shown that smoking cessation stops progression of the disease ${ }^{37}$ and reduces mortality. ${ }^{38}$

In many recent investigations on COPD detection by case finding in primary care, the percentage of newly diagnosed patients presenting with respiratory symptoms was strikingly high, attaining almost 50\%. ${ }^{31}{ }^{36}$ In our COPD group, 68\% were symptomatic with at least one symptom (cough, phlegm or dyspnoea) reported. Those patients qualify for treatment that may result in a considerable reduction in symptoms, increase in exercise capacity and improvement in health related quality of life.

Patients with airflow limitation have a high risk of lung cancer, ${ }^{39}$ coronary artery disease ${ }^{40}$ and stroke. ${ }^{41}$ A large proportion of patients with COPD die from non-pulmonary diseases. ${ }^{42} 43$ Preventive measures should be undertaken. Early diagnosis and treatment of cardiovascular diseases may be especially rewarding. ${ }^{44}$

\section{Risk factors}

Smoking was by far the most important risk factor for COPD in these patients, especially in men. However, $52 \%$ of females with COPD never smoked. Looking for other potential risk factors in never smoking women, we found that they were using coal or wood for cooking significantly more often than women with normal lung function. Biomass fuels and coal used for cooking also account for COPD among non-smoking women in other regions of the world. ${ }^{21}$

Other COPD risk factors in some of the non-smoking women were passive exposure to cigarette smoke and heavy physical work in the farm in unfavourable weather conditions, resulting in frequent respiratory infections. Passive smoking ${ }^{45}$ and recurrent lower respiratory tract infections ${ }^{46}$ may contribute to development and progression of COPD.

Our data warn against screening for COPD limited to current or ex-smokers. Half of the women diagnosed with COPD never smoked. Analysis of the relation between smoking status and symptoms in all COPD patients showed that $77 \%$ of ever smokers were symptomatic compared with $23 \%$ in never smokers. However, among 44 never smoking women with COPD, 28 (64\%) were symptomatic. By screening only smokers we would have missed a COPD diagnosis in $26 \%$ of cases. Screening only symptomatic patients would result in $32 \%$ missed cases.

\section{Socioeconomic status}

Patients with COPD declared low income and low educational level significantly more often than patients with normal respiratory function. Low educational level was found to be an independent risk factor for COPD in several large studies. ${ }^{47} 48$

\section{Study limitations}

Our study has several limitations. We used ECCS predicted values for spirometry that were developed some decades ago and may not exactly fit for the current generation of adults in Poland. The recent prediction equations for Caucasian populations $^{49}$ may have resulted in lower COPD prevalence rates. However, as ECCS predicted values are still widely used in Europe, we decided to follow a routine. Non-smoking status was not objectively verified. However, we believe that the investigated subjects' declarations were true.

Our results may not apply to other communities or countries. Good quality spirometry testing may remain a problem in some primary care settings, despite physician and nurse training programmes.

In summary, our study confirmed that COPD affected approximately $9 \%$ of the adult patients seen in a primary care setting in Poland. However, the disease was largely underdiagnosed without spirometry: only patients with severe disease $\left(\mathrm{FEV}_{1}<50 \%\right.$ predicted) had been diagnosed and treated. Large numbers of newly detected patients were symptomatic and needed treatment. Limiting screening to smokers would have reduced the number of COPD diagnoses by $26 \%$. COPD case finding should be done using office spirometry in high risk patients, smokers and subjects with respiratory symptoms.

Funding: Investigations were funded by Polish Ministry of Science Grant No 2P05D08727.

Competing interests: None.

Ethics approval: The study was approved by the local institutional review board.

\section{REFERENCES}

1. Murray RP, Lopez AD. Alternative projections of mortality and disability by cause 1990-2020: Global burden of disease study. Lancet 1997;349:1498-504.

2. Halbert RJ, Isonaka S, George D, et al. Interpreting COPD prevalence estimates: what is the true burden of disease? Chest 2003;123:1684-92

3. Pellegrino R, Viegi G, Brusasco V, et al. Interpretative strategies for lung function tests. Eur Respir J 2005;26:948-68.

4. Global Strategy for the diagnosis, management, and prevention of chronic obstructive pulmonary disease, 2006. www.goldcopd.org (accessed 14 March 2008).

5. Halbert RJ, Natoli JL, Gano A, et al. Global burden of COPD: systematic review and meta-analysis. Eur Respir J 2006;28:523-32.

6. Soriano JB, Maier WC, Egger $\mathrm{P}$, et al. Recent trends in physician diagnosed COPD in women and men in the UK. Thorax 2000;55:789-94.

7. Chapman KR. Chronic obstructive pulmonary disease: are women more susceptible than men? Clin Chest Med 2004;25:331-41.

8. Fukuchi $\mathbf{Y}$, Nishimura M, Ichinose M, et al. COPD in Japan: the Nippon COPD Epidemiology study. Respirology 2004;9:458-65.

9. Pena VS, Miravitlles M, Gabriel R, et al. Geographic variations in prevalence and underdiagnosis of COPD: results of the IBERPOC multicentre epidemiological study. Chest 2000;118:981-9.

10. Bestall JC, Paul EA, Garrod R, et al. Usefulness of the Medical Research Council (MRC) dyspnoea scale as a measure of disability in patients with chronic obstructive pulmonary disease. Thorax 1999;54:581-6.

11. Standardization of Spirometry, 1994 Update. American Thoracic Society. Am J Respir Crit Care Med 1995;152:1107-36.

12. Quanjer PH, Tammeling GJ, Cotes JE, et al. Lung volumes and forced ventilatory flows. Report Working Party Standardization of Lung Function Tests, European Community for Steel and Coal. Official Statement of the European Respiratory Society. Eur Respir J Supp/ 1993;16:5-40.

13. Plywaczewski R, Bednarek M, Jonczak L, et al. Prevalence of COPD in Warsaw population. Pneumonol Alergol Pol 2003;71:329-35.

14. Niepsuj G, Kozielski J, Niepsuj K, et al. Chronic obstructive pulmonary disease in inhabitants of Zabrze. Wiad Lek 2002;55(Suppl 1):354-9.

15. Johannessen A, Omenaas ER, Bakke PS, et al. Implications of reversibility testing on prevalence and risk factors for chronic obstructive pulmonary disease: a community study. Thorax 2005;60:842-7.

16. Hankinson JL, Odencrantz JR, Fedan KB. Spirometric reference values from a sample of the general U.S. population. Am J Respir Crit Care Med 1999;159:179-87.

17. Hardie JA, Buist AS, Vollmer WM, et al. Risk of over-diagnosis of COPD in asymptomatic elderly never-smokers. Eur Respir J 2002;20:1117-22.

18. Hansen JE, Sun XG, Wasserman K. Spirometric criteria for airway obstruction: Use percentage of FEV1/FVC ratio below the fifth percentile, not $<70 \%$. Chest 2007;131:349-55.

19. Mannino DM, Homa DM, Akinbami LJ, et al. Chronic obstructive pulmonary disease surveillance-United States, 1971-2000. MMWR Surveill Summ 2002;51:1-16.

20. Schirnhofer L, Lamprecht B, Vollmer WM, et al. COPD prevalence in Salzburg, Austria: results from the Burden of Obstructive Lung Disease (BOLD) Study. Chest 2007; 131:29-36

21. Ezzati M. Indoor air pollution and health in developing countries. Lancet 2005;366:104-6.

22. Menezes AM, Perez-Padilla R, Jardim JR, et al. Chronic obstructive pulmonary disease in five Latin American cities (the PLATINO study): a prevalence study. Lancet 2005;366:1875-81.

23. Strategies in preserving lung health and preventing COPD and associated diseases The National Lung Health Education Program (NLHEP). Chest 1998;113:123S-63S.

24. Perez-Padilla R, Vazquez-Garcia JC, Marquez MN, et al. The long-term stability of portable spirometers used in a multinational study of the prevalence of chronic obstructive pulmonary disease. Respir Care 2006;51:1167-71. 
25. Eaton T, Withy S, Garrett JE, et al. Spirometry in primary care practice: the importance of quality assurance and the impact of spirometry workshops. Chest 1999;116:416-23.

26. Dales RE, Vandemheen KL, Clinch J, et al. Spirometry in the primary care setting: influence on clinical diagnosis and management of airflow obstruction. Chest 2005; 128:2443-7.

27. Bolton CE, lonescu AA, Edwards PH, et al. Attaining a correct diagnosis of COPD in general practice. Respir Med 2005;99:493-500.

28. Lusuardi M, De Benedetto F, Paggiaro P, et al. A randomized controlled trial on office spirometry in asthma and COPD in standard general practice: data from spirometry in asthma and COPD: a comparative evaluation Italian study. Chest 2006:129:844-52.

29. Enright $\mathbf{P}$. Does screening for COPD by primary care physicians have the potential to cause more harm than good? Chest 2006;129:833-5

30. Chavannes N, Schermer T, Akkermans R, et al. Impact of spirometry on GP' diagnostic differentiation and decision-making. Respir Med 2004;98:1124-30.

31. Vandevoorde J, Verbanck S, Gijssels L, et al. Early detection of COPD: a case finding study in general practice. Respir Med 2007;101:525-30.

32. Lancaster T, Stead L, Silagy C, et al. Effectiveness of interventions to help people stop smoking: findings from the Cochrane Library. BMJ 2000;321:355-8.

33. Tashkin D, Kanner R, Bailey W, et al. Smoking cessation in patients with chronic obstructive pulmonary disease: a double-blind, placebo-controlled, randomised trial. Lancet 2001;357:1571-5.

34. Bednarek M, Gorecka D, Wielgomas J, et al. Smokers with airway obstruction are more likely to quit smoking. Thorax 2006;61:869-73.

35. Stratelis G, Molstad S, Jakobsson P, et al. The impact of repeated spirometry and smoking cessation advice on smokers with mild COPD. Scand J Prim Health Care 2006;24:133-9.

36. Buffels J, Degryse J, Decramer M, et al. Spirometry and smoking cessation advice in general practice: a randomised clinical trial. Respir Med 2006;100:2012-17.

37. Anthonisen NR, Connett JE, Murray RP. Smoking and lung function of Lung Health Study participants after 11 years. Am J Respir Crit Care Med 2002;166:675-9.
38. Anthonisen NR, Skeans MA, Wise RA, et al. The effects of a smoking cessation intervention on 14.5-year mortality: a randomized clinical trial. Ann Intern Med 2005; 142:233-9.

39. Mannino DM, Aguayo SM, Petty TL, et al. Low lung function and incident lung cancer in the United States: data From the First National Health and Nutrition Examination Survey follow-up. Arch Intern Med 2003;163:1475-80.

40. Curkendall SM, DeLuise C, Jones JK, et al. Cardiovascular disease in patients with chronic obstructive pulmonary disease, Saskatchewan Canada cardiovascular disease in COPD patients. Ann Epidemiol 2006;16:63-70.

41. Truelsen T, Prescott E, Lange P, et al. Lung function and risk of fatal and non-fatal stroke. The Copenhagen City Heart Study. Int J Epidemiol 2001;30:145-51.

42. Mannino DM, Buist AS, Petty TL, et al. Lung function and mortality in the United States: data from the First National Health and Nutrition Examination Survey follow up study. Thorax 2003;58:388-93.

43. Mannino DM, Doherty DE, Buist AS. Global Initiative on Obstructive Lung Disease (GOLD) classification of lung disease and mortality: findings from the Atherosclerosis Risk in Communities (ARIC) study. Respir Med 2006;100:115-22.

44. Frost FJ, Petersen $\mathrm{H}$, Tollestrup $\mathrm{K}$, et al. Influenza and COPD mortality protection as pleiotropic, dose-dependent effects of statins. Chest 2007;131:1006-12.

45. Eisner MD, Balmes J, Katz PP, et al. Lifetime environmental tobacco smoke exposure and the risk of chronic obstructive pulmonary disease. Environ Health 2005:4:7.

46. Retamales I, Elliott WM, Meshi B, et al. Amplification of inflammation in emphysema and its association with latent adenoviral infection. Am J Respir Crit Care Med 2001;164:469-73.

47. Bakke PS, Hanoa R, Gulsvik A. Educational level and obstructive lung disease given smoking habits and occupational airborne exposure: a Norwegian community study. Am J Epidemiol 1995; 141:1080-8.

48. Prescott $E$, Lange $P$, Vestbo J. Socioeconomic status, lung function and admission to hospital for COPD: results from the Copenhagen City Heart Study. Eur Respir J 1999;13:1109-14.

49. Falaschetti E, Laiho J, Primatesta $\mathrm{P}$, et al. Prediction equations for normal and low lung function from the Health Survey for England. Eur Respir J 2004;23:456-63. 